\title{
Sound advice on science
}

\author{
Integrating multiple sources of advice into a coherent science policy is a challenge. The United Kingdom promotes \\ direct communication between scientists and high-level policy makers, a practice the United States should emulate.
}

$\mathbf{T}$ he question 'Who advises?' is hardly less important than 'Who governs?', argues Gregg Herken in his book on the history of scientific advice to the US government ${ }^{1}$. With scientific disciplines becoming increasingly specialized, this view carries considerable weight today. Many government decisions-such as policies on drug addiction, climate change or stem cell technologydepend at least partially on technical or scientific analysis. Accurate scientific advice is not the only ingredient in formulating successful policy, of course, but unbiased advisors are a necessary prerequisite for enabling government officials (who are rarely scientifically trained) to translate complex findings into policy.

The problem is not a shortage of opinions; as a report by the Federation of American Scientists puts it, "No one with power in Washington suffers from lack of advice." Instead, the difficulty is in choosing where to look for assistance among corporations, advocacy groups, non-governmental organizations and government-sponsored scientific bodies. The US and the UK take different approaches to navigating this thicket of information.

UK science policy is mainly coordinated by the Office of Science and Innovation (OSI). The guidelines for scientific analysis in policy making emphasize the need for an evidence-based approach and the importance of peer review. The OSI periodically invites scientists to discuss possible developments over the next 20 years in areas of interest, by way of its 'Foresight' projects. A recent project on Brain Science, Addiction and Drugs produced a scientific review of the field, along with strategic choices that the government is likely to face in the future. The head of OSI then presented these findings to the Prime Minister and the cabinet. The report raised some controversial topics, including the potential for reducing harm from recreational drug use through preventive medicine, such as vaccines, and whether cognitive enhancers for healthy people should be freely available, regulated or banned. The direct interaction between scientists and top policy makers provided by the Foresight projects is especially important for emotionally laden public-health issues like addiction.

The situation in the United States is more complicated. US science policy is largely managed by the Office of Science and Technology Policy (OSTP), which coordinates with the President's Council of Advisors on Science and Technology (PCAST) and the National Science and Technology Council (NSTC). In theory, these organizations should have direct access to the White House; the NSTC is a cabinet-level council, and, as implied by its name, PCAST is expected to advise the president. In practice, however, the roles and access of these organizations depend on the preferences of the incumbent. For example, unlike in previous administrations, the PCAST now reports to the OSTP director, not to the president. Compared to other advisory institutions (such as the National Security Council), there is little continuity in science advice between administrations, making the sort of long-term policy making exemplified by the Foresight projects very difficult — a problem compounded by the scarcity of direct interaction between scientists and politicians.

Scientists (and those who rely on them) are not happy with this state of affairs. The Federation of American Scientists recently recommended the resurrection of the Office of Technology Assessment to "assemble external expertise and conduct detailed analysis of complex technical subjects." This role would normally be filled by the OSTP, but the OSTP is significantly weaker under the present administration. Only two of four associate director positions are currently filled, and the offices have been relocated away from key White House staff. Organizations such as the newly formed Scientists and Engineers for America articulate the perception that current US science policy is largely based on political motives, rather than on scientific findings. This group urges candidates to support a scientific Bill of Rights, including the provision that appointments to federal scientific advisory positions should be based on the candidate's scientific qualifications, rather than political affiliation or ideology. Scientific competence should be a given for advisors on science policy, and the sidelining of scientific opinion is likely to be harmful in the long term, as can already be seen in policies on stem-cell research. The US would be well advised to take a page from UK government policy by ensuring that leading scientists have direct access to top policy makers.

Of course, even when the system is working well, there is no guarantee that the recommendations of scientific advisory bodies will be followed. The report on the Brain Sciences, Addiction and Drugs Project, for example, is currently undergoing review by the Academy of Medical Sciences to examine implications for future health policy. Such policy, like any other government decisions, obviously needs to take other factors (such as public acceptability) into account. However, it remains important for science policy to be based on evidence, and we hope that the recommendations of the project find their way into government policy in some form.

The system used by the UK Foresight project has its limitations as well. Inviting individual scientists, rather than scientific bodies such as the US National Academies, to comment on issues runs the risk of having science policy driven by an 'old boys' network' of select scientists. Nor is it likely that scientists will be more successful at crystal-gazing than other people. However, grounding predictions in an understanding of current scientific findings is a good first step, and basing policy decisions on this understanding is even better. As scientific issues become ever more complex, we cannot afford to underestimate the importance of seeking advice from those who understand the issues best.

1. Herken, G. Cardinal Choices: Presidential Science Advising from the Atomic Bomb to SDI (Oxford University Press, Oxford, UK, 1992).

View more background material on Connotea at http://www.connotea.org/user/ NatNeurosci/tag/editorial200612. 